SHORT REPORT

\title{
A users guide for reducing the pain of local anaesthetic administration
}

\author{
O Quaba, J S Huntley, H Bahia, D W McKeown
}

Emerg Med J 2005;22:188-189. doi: 10.1136/emj.2003.012070

Local anaesthetics (LAs) are used by medical practitioners in a number of clinical settings. The choice of agent and mode of administration is influenced by their experience, speciality and knowledge of the evidence base.

Patients often express concern about the discomfort experienced during injection. Although short lived, the pain of LA administration in some patients is severe enough for them to decline future surgery. Methods to minimise the pain of LA administration relate to (1) the patient, (2) the LA, and (3) the injection technique (table 1). This article aims to provide a practical guide to doctors of all specialities who use LAs.

\section{FACTORS RELATING TO THE PATIENT}

\section{Reassurance and distraction}

Explanation, encouragement, and reassurance play a key role in reducing the pain of LA administration. A calm, unhurried and confident manner in the administrator is helpful. Many practitioners will distract the patient using conversation or music. Some advise patients to concentrate on deep, slow breathing. Others distract patients by rubbing or pinching the skin close to the injection site in order to stimulate larger Afibres to inhibit the stimuli from C-fibres conveying pain to the spinal cord. ${ }^{1}$ More recently, Melzac (1999), emphasised the importance of genetic, behavioural, and cognitive factors in the evoked experience of pain. ${ }^{2}$

Sedation is sometimes necessary but not recommended on a routine basis.

\section{Prior application of topical anaesthetic}

Desensitisation of the skin or mucous membranes by topical anaesthesia prior to injection of LA reduces pain. Several studies have shown reduced pain when topical anaesthesia is used prior to LA administration in dental procedures, ${ }^{34}$ cannulation, ${ }^{56}$ carpal tunnel release, ${ }^{7}$ skin grafting, ${ }^{89}$ and ear surgery..$^{10}$

EMLA cream, a eutectic mixture of the local anaesthetics prilocaine and lignocaine, is one of the most commonly used preparations available. AMETOP, a topical amethocaine, which is faster acting and longer lasting, ${ }^{11}$ may also be used, although there is a slightly higher incidence of allergy and minor skin irritation. These need to be applied for at least half an hour prior to the procedure to ensure maximum efficacy. Ethyl Chloride spray is also effective as a superficial anaesthetic to 'freeze' the skin prior to needle puncture. ${ }^{12}$

However, Lal et al, found that cognitive-behavioural distraction therapy by an experienced child play specialist was just as effective in reducing pain as topical application of EMLA during venepuncture in children. ${ }^{13}$

\section{FACTORS RELATING TO THE LA}

\section{Warming}

Several studies have shown that warming of LA solution prior to injection reduces pain. However, other studies have suggested little or no effect. Arndt et al, claim no significant benefit between LA warmed to body temperature $\left(37^{\circ} \mathrm{C}\right)$ compared with that at room temperature $\left(21^{\circ} \mathrm{C}\right) . .^{14}$ Bell et al (1996) and Alonso et al (1993), however, have shown benefit in warming the solution to $37^{\circ} \mathrm{C}$ and $42^{\circ} \mathrm{C}$ in prospective blinded randomised control studies. ${ }^{15}{ }^{16}$ With new policies of refrigerating LA at $4^{\circ} \mathrm{C}$, particularly those containing adrenaline, there may indeed be a benefit to warming the solution to near body temperature.

LA activity is strongly pH dependent, being higher at raised (alkaline) pH when more of the particles are in the unionised state. It is postulated that warming and buffering (see below) may reduce the pain of LA by shifting the dissociation constant so that a greater proportion of particles are in the uncharged state. Uncharged particles diffuse more readily into the nerve, leading to more rapid and effective inhibition of nerve conduction. ${ }^{17}$

\section{Buffering}

Several double blind randomised control trials have shown benefit in pain reduction when LA solutions are buffered. ${ }^{18} 19$ This particularly applies to the amide group of LAs such as lignocaine and bupivacaine. Addition of $8.4 \%$ sodium bicarbonate to LA solution regardless of presence of adrenaline and LA concentration is enough to buffer the solution without risk of precipitation. ${ }^{20}$

Research has shown that the advantages of buffered LA are still evident in terms of speed of onset, duration of action, and anaesthetic effect for up to l week of storage. However, most units dispose of any opened vials of LA at the end of each day. $1 \mathrm{ml}$ of bicarbonate $(8.4 \%)$ can be added to every $9 \mathrm{ml}$ of LA solution.

Table 1 Methods to minimise pain of LA administration

THE PATIENT

1. Reassurance, distraction

2. Topical anaesthesia prior to infiltration

THE LA AGENT

3. Warming $-37-42^{\circ} \mathrm{C}$

4. Buffering $-8.4 \%$ Sodium Bicarbonate $(1 \mathrm{ml} / 9 \mathrm{ml} \mathrm{LA})$

THE INJECTION TECHNIQUE

5. Fine (27-30 gauge) and long $(>1$ inch) needles

6. Slow injection

7. Use smallest volume of solution necessary

8. Infiltrate through wound edges

9. Inject from 'looser' subdermal to 'tighter' dermal

10. Block individual nerves

LA, local anaesthetic

Abbreviations: LA, local anaesthestics 
FACTORS RELATING TO THE INJECTION TECHNIQUE 5. Type of needle - fine and long

It is known that the finer a needle is, the less pain is caused on injection. ${ }^{21}$ It is common for most practitioners to use a 25 gauge needle. Dental syringes often have finer needles (27 and 30 gauge). It is therefore recommended that at least a 27 gauge needle is used for infiltration.

Part of the pain of LA administration occurs at the initial penetration of the skin. A long needle allows a wider area to be infiltrated below the surface with a single skin puncture thereby limiting the number of needle punctures required.

Diabetic syringes with short 30 gauge needles may be used to infiltrate a small amount of LA initially before a larger needle is introduced through the same area.

\section{Injecting slowly}

Pain can also be experienced due to the expansion of subcutaneous tissues during the infiltration of LA. Injecting slowly therefore has an important role in minimising pain. ${ }^{1422} 23$ Greater control and accuracy of the rate of injection can be gained by using the smallest volume syringe available for the amount of LA needed. All too often doctors use a $10 \mathrm{ml}$ syringe to inject 3-4 mls of solution.

\section{Use smallest volume of solution necessary}

Many procedures require no more than 1-2 mls of LA for effective anaesthesia. Using low volume syringes also reduces the chance of an excessive volume being used. Use of the smallest volume necessary for anaesthesia is preferable as an excess volume is unlikely to be of benefit and may cause more pain.

\section{Infiltrate through wound edges}

It is obvious that, where possible, infiltration should be performed through the wound edges in lacerated or incised wounds. This has been shown to be of benefit in randomised blinded trials. ${ }^{24}$

\section{Inject from 'looser' subdermal to 'tighter' intradermal skin}

It is well known clinically that injection into 'tighter' tissues such as the lips or tip of the nose can be very painful. Arndt et al, showed that infiltration at a deeper subdermal level was less painful than at a superficial intradermal injection, although slower to work. ${ }^{14}$

\section{Block nerves where possible}

A good knowledge of the anatomy of the peripheral nerve supply is advantageous to successfully administer regional anaesthesia. This is particularly useful where areas contain a high density of sensory nerve endings, which may make local infiltration very painful. Examples include an infra-orbital nerve block to anaesthetise the very sensitive upper lip, or a ring/metacarpal block to anaesthetise the finger.

Combinations of nerves may be advantageously blocked to avoid the need for large volumes of injected LA - for example median, radial and ulnar nerves in the 'wrist block' or the lower limb equivalent, the ankle block.

\section{Authors' affiliations}

O Quaba, Aberdeen Royal Infirmary, Aberdeen, UK

J S Huntley, D W McKeown, New Royal Infirmary of Edinburgh,

Edinburgh, UK

H Bahia, St. John's Hospital Livingston, UK

Correspondence to: Omar Quaba, Specialist Registrar, Department of Plastic Surgery, Ward 39, Aberdeen Royal Infimary, Aberdeen, AB25 2ZA, UK; omarquaba@hotmail.com

\section{REFERENCES}

1 Melzack R, Wall P. Pain mechanism: new theory. Science. 1965;150: 971 \& 979).

2 Melzack R. From the gate to the neuromatrix. Pain 1999;(Suppl 6):S121-6.

3 McMillan AS, Walshaw D, Meechan JG. The efficacy of Emla and 5\% lignocaine gel for anaesthesia of human gingival mucosa. British Journal of Oral \& Maxillofacial Surgery 2002;38(1):58-61.

4 Meechan JG. Intra-oral topical anaesthetics: a review. J Dent 2000;28(1):3-14.

5 Maunuksela EL, Korpela R. Double-blind evaluation of a lignocaine-prilocaine cream (EMLA) in children. Effect on the pain associated with venous cannulation. Br J Anaesth 1986;58(11):1242-5.

6 Eichenfield LF, Funk A, Fallon-Friedlander S, et al. A clinical study to evaluate the efficacy of ELA-Max (4\% liposomal lidocaine) as compared with eutectic mixture of local anesthetics cream for pain reduction of venepuncture in children. Pediatrics 2002;109(6):1093-9.

7 Lawrence TM, Desai WV. Topical anaesthesia to reduce pain associated with carpal tunnel surgery. J Hand Surg [Br] 2002;27(5):462-4.

8 Small J, Wallace RG, Millar R, et al. Pain-free cutting of split skin grafts by application of a percutaneous local anaesthetic cream. Br J Plast Surg 1988:41(5):539-43.

9 Goodacre TE, Sanders R, Watts DA, et al. Split skin grafting using topical local anaesthesia (EMLA): a comparison with infiltrated anaesthesia. Br J Plast Surg 1988;41(5):533-8.

10 Slator $\mathbf{R}$, Goodacre TE. EMLA cream on the ears--is it effective? A prospective, randomised controlled trial of the efficacy of topical anaesthetic cream in reducing the pain of local anaesthetic infiltration for prominent ear correction. Br J Plast Surg 1995;48(3):150-3.

11 Russell SC, Doyle E. A risk-benefit assessment of topical percutaneous local anaesthetics in children. Drug Saf 1997; 16(4):279-87.

12 Armstrong P, Young C, McKeown DW. Ethyl Chloride and venepuncture pain: a comparison with intradermal lidocaine. Can J Anaesth 1990;37(6):656-658.

13 Lal MK, McClelland J, Phillips J, et al. Comparison of EMLA cream versus placebo in children receiving distraction therapy for venepuncture. Acta Paediatrica 2001;90(2): 154-9.

14 Arndt KA, Burton C, Noe JM. Minimizing the pain of local anesthesia. Plast Reconstr Surg 1983;72(5):676-9.

15 Bell RW, Butt ZA, Gardner RF. Warming lignocaine reduces the pain of injection during local anaesthetic eyelid surgery. Eye 1996; 10(5):558-60.

16 Alonso PE, Perula LA, Rioja LF. Pain-temperature relation in the application of local anaesthesia. Br J Plast Surg 1993;46(1):76-8.

17 Richie JM, Greengard P. On the mode of action of local anaesthetics. Ann Rev Pharmaco 1966;6:405-30.

18 Masters JE. Randomised control trial of $\mathrm{pH}$ buffered lignocaine with adrenaline in outpatient operations. Br J Plast Surg 1998;51(5):385-7.

19 Christoph RA, Buchanan L, Begalla K, et al. Pain reduction in local anesthetic administration through $\mathrm{pH}$ buffering. Ann Emerg Med 1988;17(2):117-20.

20 Milner QJ, Guard BC, Allen JG. Alkalinization of amide local anaesthetics by addition of $1 \%$ sodium bicarbonate solution. Eur J Anaesthesiol 2000;17(1):38-42.

21 Edlich RF, Smith JF, Mayer NE, et al. Performance of disposable needle syringe systems for local anesthesia. J Emerg Med 1987;5(2):83-90.

22 Jones CM, Heidmann J, Gerrish AC. Children's ratings of dental injection and treatment pain, and the influence of the time taken to administer the injection. Int J Paediatr Dent 1995;5(2):81-5.

23 Serour F, Mandelberg A, Mori J. Slow injection of local anaesthetic will decrease pain during dorsal penile nerve block. Acta Anaesthesiol Scand 1998;42(8):926-928.

24 Bartfield JM, Sokaris SJ, Raccio-Robak N. Local anesthesia for lacerations: pain of infiltration inside vs. outside the wound. Acad Emerg Med 1998;5(2):100-4 